\title{
VARIETY OF DRUGS SOLD WITHOUT PRESCRIPTION FOR COMMONLY PRESENTING COMPLAINTS IN RURAL AND URBAN PHARMACIES OF FAISALABAD DISTRICT
}

Muhammad Hamza Ranaa, Muhammad Husnainª, Muhammad Hamza Iqbala, Noor-i-Kiran Naeem, Muhammad Usman', Yasir Yaqoob ${ }^{\mathrm{d}}$

a4th Year MBBS student, Aziz Fatima Medical and Dental College, Faisalabad.

${ }^{b}$ Assistant Professor, Department of Medical Education, Aziz Fatima Medical and Dental College, Faisalabad.

'Associate Professor, Department of Pathology, Aziz Fatimah Medical and Dental College, Faisalabad. dSenior Registrar, District Headquarter (DHQ) Hospital, Faisalabad.

\section{ABSTRACT:}

BACKGROUND \& OBJECTIVE: Pharmacies play an important role in provision of health care to the community. The objective of the study was to explore the reasons for a variety of drugs sold without prescription for commonly presenting complaints in Rural and Urban Pharmacies of Faisalabad District. METHODOLOGY: This explanatory sequential mixed method design involved workers from twentyfive pharmacies from urban and rural areas of Faisalabad from February to July 2020. After obtaining informed consent, fifty pharmacy workers filled a pre-designed questionnaire (followed by twentyfive semi-structured, individual, face-to-face interviews. Quantitative data was analyzed via SPSS software and transcribed interviews were organized manually for data analysis.

RESULTS: Response rate was $76.2 \%$. As reported by the pharmacists, $40 \%$ and $90 \%$ of urban and rural population respectively came to pharmacies for over the counter drugs. Fifty percent belonged to middle class among urban and $70 \%$ belonged to rural population. Data analysis led to formation of 36 codes, 6 sub themes and 3 themes. Out of the four reasons quoted by the pharmacists (time constraints, lack of basic facility locally, financial constraints, and myths/fear of going to doctor), there was a statistically significant difference for rural population going directly to pharmacies because of financial constraints.

CONCLUSION: Lack of education and financial constraints are the leading influential factors for people taking over-the-counter drugs in both rural and urban population, with time constraints being at the top list among urban population. Robust policies and public health care programs can lead to public awareness at large and can help in creating an environment of health care provision with MINIMAL RISKS.

KEYWORDS: Over-the-counter drugs, Pharmacy, Community, Urban, Rural.

https://doi.org/10.37723/jumdc.v12i3.549

How to cite this:

Rana MH, Husnain M, Iqbal MH, Naeem NK, Usman M, Yaqoob Y. Variety of Drugs sold without prescription for commonly presenting complaints in rural and urban pharmacies of Faisalabad district. Journal of University Medical \& Dental College. 2021;12(3):204-210.https://doi.org/10.37723/ jumdc.v12i3.549

This is an Open Access article distributed under the terms of the Creative Commons Attribution License (http://creativecommons.org/licenses/by/4.0), which permits unrestricted use, distribution, and reproduction in any medium provided the original work is properly cited. 


\section{INTRODUCTION:}

World Health Organization (WHO) defines health as a state of complete physical, mental and social well-being and not merely disease or infirmity ${ }^{[1]}$. Studies have revealed that the multidisciplinary approach and expertise are key factors for achieving ultimate population health goals ${ }^{[2]}$. In order to achieve the aim of health for all, it is optimum for different health professionals to work in collaboration for fulfilling the health needs of the patient ${ }^{[3]}$. Over the last few decades, pharmacies are have been evolving to promote pharmaceutical care and standard provision of care for patients ${ }^{[4]}$. In essence, the concept of pharmaceutical care has revolutionized and enabled accountability in inpatient care to achieve optimum results with drug therapy ${ }^{[5]}$. Pharmacists are playing a significant role in dispensing better drugs to provide provisional health care services, especially in developing countries ${ }^{[6]}$.

Over the past few years, WHO has played a vital role in encouraging pharmacists globally[7].Moreover, WHO has also ensured and emphasized on the quality assurance and constructive implication of drugs $^{[8]}$. The international pharmaceutical federation and WHO have developed the "Seven-star pharmacists" guide. This guide focuses on better decision making, caregiving, active communication, life long learning and good managing skills, posing good leadership qualities with the ability to be a teacher and researcher ${ }^{[9]}$. With the rising interest and contribution to the pharmacy profession, the World Health Organization suggests the ratio of one drug for each 2000 population to provide better health care services.

The profession of pharmacy and pharmacists varies significantly different from one country to another. Each country posses its own risk and barriers for the development of better pharmaceutical care facilities such as qualified pharmacists or no implication of pharmaceutical health policy ${ }^{[10]}$.One of the most promising developing economically growing countries, Malaysia, also enlist an acute shortage of pharmacists with a ratio of only $1: 6207^{[11,12]}$. There is no such distinction between a doctor and pharmacist, as the doctor himself prescribes and dispenses medicine to the patient. Although the legislation was raised 20 years ago for pharmaceutical care, the only void in the policy is the shortage of pharmacists and concern of objection in the separation of medical practitioners ${ }^{[13,14]}$. The African nation also faces scarce availability of pharmacists, with a total of only 619 pharmacists serving the mass population of 2.9 million $^{[15]}$.

\section{Corresponding Author:}

Dr. Noor-i-Kiran Naeem

Assistant Professor Department of Medical Education, Aziz Fatima Medical and Dental College Faisalabad

Email: noorikiran@yahoo.com

In Pakistan, more than 8100 pharmacists available, with 2836 working in the public sector and 5023 working in private settings. The total number of pharmacists in Pakistan, 55\% are engaged in the production of pharmaceuticals $15 \%$ of them working at the federal and provincial drug control authority and hospital pharmacy level - with another $15 \%$ in sales and marketing of medicines, $10 \%$ in community pharmacy, and the rest $5 \%$ in teaching and research ${ }^{[16]}$. In contrast to the developed countries, there is no proper recognition and drug regulatory authority in Pakistan. The reasons for these instabilities include the lack of pharmacies and pharmacists in public health services, which leads to the lack of community-pharmacist interaction ${ }^{[17]}$.

Lack of updated reforms have led to a gap where the patients have been reportedly going directly to the pharmacists to get several over the counter drugs as well as other drugs for various reasons instead of reporting to a physician first for self-medication ${ }^{[18]}$. Over the counter drugs include traditional preparations deregulated from the previous state of "Prescription drugs," also named On the counter drugs. Policies on dispensing and consumption of over the counter drugs vary globally. In Europen nations, only pharmacies distribute over the counter drugs, but in the United stated, over-the-counter drugs are sold on general retail outlets ${ }^{[19]}$. In Pakistan, a significant surge in the consumption of over-thecounter drug sales has raised alarming concerns to the local governing bodies ${ }^{[20]}$.

According to a study, more than $90 \%$ of the adults consuming over-the-counter drugs for 
various ailments were unaware of potential side effects ${ }^{[21]}$. The aim of this study was to explore the reasons for variety of drugs sold without a prescription for commonly presenting complaints in rural and urban pharmacies of Faisalabad District.

\section{METHODOLOGY:}

This study was conducted using an explanatory sequential mixed method design in a two-phase scheme from February to July 2020.In the first phase, we gathered quantitative data and analyzed the findings, and in the second, we used the results to design(or build onto) the qualitative part. The general purpose of this project was to collect qualitative data that would help explain in more detail the initial quantitative results and explore them in more depth. Ethical approval was taken vide reference number dme/889-20 dated 17th February 2020 from Aziz Fatimah Medical and Dental College, Faisalabad.

After the Ethical Board approval, a study proforma was designed after the literature review and was distributed among fifty employees and owners of twenty-five pharmacies of urban and rural areas in and around Faisalabad.

The proforma inquired about demographic details of pharmacies, drugs sold over the counter, common symptoms with which the people presented to these pharmacies, and the reason behind going there. The participants were asked to rank the above reasons according to importance on a five-point Likert scale. Continuous data were represented by means and standard deviation, and categorical data were represented by frequencies and proportions. A student t-test of significance was applied, taking a $p<0.005$ significant between the stated reasons in urban and rural pharmacies.

This was followed by twenty-five individual face to face interviews to explore in depth the reasons and factors behind patients taking over the counter drugs from pharmacies in bother urbanrural settings. Out of these, fifteen were from urban pharmacies, and ten were conducted from rural pharmacies. Following the guidelines of a qualitative study, the numbers of interviews were done until the data saturation was observed.

To maintain the quality of the study, the interviews were recorded on two different devices. The recordings were transcribed completely so as not to miss any information. Data analysis was done through manual coding with the formation of open codes learning to a generation of sub-themes and themes. The credibility of the study was ensured by doing member checking, intercoder reliability, and using the technique of reframing questions. Transferability, dependability, and conformability were done for quality assurance of the study.Test of significance was applied to the two groups of pharmacy locations (urban and rural) for the rated reasons.

\section{RESULTS:}

A total of sixty-five participants were invited for filling the questionnaire, but fifty returned, giving a response rate of $76.9 \%$. Descriptive statistics were used to analyze demographic variables and determine the reasons for patients getting over-the-counter drugs from pharmacies and not attending a clinic as perceived by the participants. The mean score was calculated for each of the categories of reasons. Table-I shows participants' characteristics in the study with equal representation of rural and urban pharmacies. All workers were male in the study.

Table-I: Demographic data of Participants.

\begin{tabular}{|c|c|c|}
\hline Characteristic & Frequency & Percentage \\
\hline \multicolumn{3}{|c|}{ Age group } \\
\hline $\mathbf{2 5 - 4 0}$ & 20 & $40 \%$ \\
\hline $\mathbf{4 0 - 6 0}$ & 30 & $60 \%$ \\
\hline \multicolumn{2}{|c|}{ Location of Pharmacies } \\
\hline Urban & 27 & $54 \%$ \\
\hline Rural & 23 & $46 \%$ \\
\hline
\end{tabular}

Table-II shows the reported percentages of patients coming to pharmacies to for purchasing drugs as perceived by the workers and owners of the pharmacies. 
Table-II: Reported percentage of patients coming to Pharmacies.

\begin{tabular}{|c|c|c|}
\hline Characteristic & Urban & Rural \\
\hline \multicolumn{2}{|c|}{ On basis of doctor's prescription } \\
\hline With Prescription & $60 \%$ & $10 \%$ \\
\hline Without Prescription & $40 \%$ & $90 \%$ \\
\hline \multicolumn{3}{|c|}{ Gender } \\
\hline Male & $55 \%$ & $54 \%$ \\
\hline Female & $45 \%$ & $46 \%$ \\
\hline Socioeconomic status \\
\hline Lower & $25 \%$ & $70 \%$ \\
\hline Middle & $50 \%$ & $15 \%$ \\
\hline Upper & $25 \%$ & $15 \%$ \\
\hline
\end{tabular}

During phase two, twenty participants underwent individual, face-to-face interviews ( 15 from urban pharmacies and 10 from rural pharmacies). The aim of interviews was to explore the reasons which were quoted by the participants in greater depth. A 36 codes were got leading to 6 sub themes and 3 themes below:

\section{Personal Factors}

a. Self-medication

b. Myths and fears about going to a doctor

c. Time constraints

2. External Factors

a. Lack of local health Center

b. Lack of local doctor

3. Financial Factors

a. Economic class

Table-III depicts various subthemes got from a thematic analysis of the interview and workers' rating of those reasons for drug purchase. It can be seen that workers from rural pharmacies ranked "financial constraints" as the topmost influencing factor for requesting drugs without prescription, whereas those from urban pharmacies ranked 'Self-medication" as the topmost reason. There were significant results among the urban and rural data set.

Table-III: Reasons for requesting pharmacies for drug purchases without doctors' prescriptions.

\begin{tabular}{|c|c|c|c|}
\hline Characteristic & $\begin{array}{c}\text { Urban Pharmacy } \\
(\mathbf{n = 2 7})\end{array}$ & $\begin{array}{c}\text { Rural Pharmacy } \\
(\mathbf{n = 2 3 )}\end{array}$ & p-value \\
\hline Self-Medication & $4.51+0.49$ & $4.05+0.53$ & 0.003 \\
\hline Lack of basic facility locally & $3.38+0.57$ & $4.46+0.552$ & 0.000 \\
\hline Financial Constraints & $3.88+0.506$ & $4.24+0.51$ & 0.016 \\
\hline $\begin{array}{c}\text { Myths and fears of going to } \\
\text { doctor }\end{array}$ & $3.93+0.59$ & $4.31+0.62$ & 0.032 \\
\hline
\end{tabular}

Table-IV shows the themes and subthemes found in the study regarding perceived reasons for patients reporting directly to the pharmacies for buying medicines.

Table-IV: : Breakup of perceived reasons for buying medicine without prescription.

\begin{tabular}{|c|c|c|c|c|}
\hline \multirow{2}{*}{ Themes } & \multirow{2}{*}{ Sub Themes } & \multicolumn{3}{|c|}{ No. of Codes (125) } \\
\cline { 3 - 5 } & & Total & $\begin{array}{c}\text { Urban } \\
\text { pharmacy } \\
\text { workers }\end{array}$ & $\begin{array}{c}\text { Rural } \\
\text { Pharmacy } \\
\text { workers }\end{array}$ \\
\hline \multirow{3}{*}{ Personal Factors } & Self- medication & 25 & $17(68.0)$ & $8(32.0)$ \\
\cline { 2 - 5 } & $\begin{array}{c}\text { Myths and fears about } \\
\text { going to doctor }\end{array}$ & 16 & $2(12.5)$ & $14(87.5)$ \\
\cline { 2 - 5 } & Time Constraints & 23 & $15(65.2)$ & $8(34.8)$ \\
\hline External factors & Lack of local health facility & 13 & $5(38.5)$ & $8(61.5)$ \\
\hline Socioeconomic factors & Economic class & 25 & $10(40.0)$ & $15(60.0)$ \\
\hline
\end{tabular}


Interviewees had a range of impressions about factors influencing patients to buy drugs directly from the pharmacies; few of the quotations are as followed. Interview R-10 explained financial status as being most common reason which prevented patients attending doctor and then coming to pharmacies to buy his prescribed medicine. R-10 said: "..... mostly they avoid spending extra money on a doctor's visit and prefer coming here directly as they can then drugs directly. This saves money and time".

The time constraints factor was also reported by various workers from urban pharmacies as well. Few of them keenly explained about the lack of health facility and local doctor availability in their region. Interviewee U-9, one worker from urban pharmacy narrated: "People do not prefer local doctor in nearby Basic health clinic, they would want either a very Hi-Fi hospital where they can go or they would come directly to us to buy basic medicine." Interviewee R-14 explained,"... we have a local clinic, but the doctor is hardly there, so people do not go there..."

Much stress was made by workers from rural pharmacies about the beliefs of people coming to rural pharmacies about doctor's visits. Interviewee R-3 said, "Mostly they think that their case would be worsened if the patient is taken to a doctor, that she would turn a normal delivery case into an operation one...."

Last, people preferred going directly to the pharmacies to get drugs and were into the habit of self-medication.

\section{DISCUSSION:}

The results of this study show that the frequency of people visiting health care pharmacies in urban pharmacies $(F=27,54 \%)$ is slightly more than in rural areas $(F=23,46 \%)$. People with age groups ranging from 40 to 60 years visit more frequently than those of the age group 25-40. Similarly, Table II illustrates the percentage of people visiting pharmacies with prescription $(60 \%)$ is more in an urban area while in rural settings $(10 \%)$. Over 90 percent of people in rural pharmacies visit without prescription. This shows the concern of people living in urban areas seeking health care services. People living in urban areas are more literate, and the urban population is more affluent ${ }^{[19]}$. However, a significant proportion of people living in rural areas are illiterate and practice superstitions. Lack of necessary health care resources in Rural health care settings also creates a significant difference between urban environments. ${ }^{[21]}$ the socioeconomic background was seen to have a significant influence on the mass population visiting pharmacies without a prescription. Most of the people in rural areas visiting directly to the pharmacies without prescription belonged to low socioeconomic backgrounds. This was because of the availability of limited resources and health care facilities in rural settings. They consider this most cost-effective to visit the pharmacy while visiting the doctor first. Pharmacies in rural settings are non-prolific and don't follow the standards to dispense medications [22].

The study also evaluates the main reason behind visiting the pharmacies without a prescription as financial constraints. Results reveal that in the rural population $(4.24+0.51)$, people tend to visit pharmacies without visiting the doctor and opt for self medications without knowing the potential outcomes of the drugs. Lack of awareness and education forces them not to see the doctor as this will cause them to pay extra charges for the provision of health care. Contrary to that, people living in rural settings also believe and practice various myths and superstitions. Another study supports these barriers elaborates that rural people consider sadness and happiness to be the cause of mental disorders and a prevailing or life-threatening disease is due to God's punishment ${ }^{[23]}$. However, all these superstitons are baseless according to scientific knowledge, as science provides a reason for every happening.

The scarcity of primary health care facilities and doctors available is one of the predisposing factors compelling the residents of rural areas to move towards pharmacies. Not much attention is paid for the provision of better health care facilities. Due to the high population and inadequate resources available, there is a lack of necessary health care facilities in rural areas ${ }^{[5]}$.

\section{CONCLUSION:}

Lack of education and financial constraints are the leading influential factors for people taking over the counter drugs in both rural and urban population with time constraints being at the top list among urban population. Robust poilicies and 
public health care programs can lead to public awareness at large and can help in creating a an environment of health care provision with minimal risks.

ACKNOWLEDGEMENT: None. CONFLICT OF INTEREST: None. GRANT SUPPORT \& FINANCIAL DISCLOSURE:

None.

\section{REFERENCES.}

1. McCartney G, Popham F, McMaster R, Cumbers A. Defining health and health inequalities. Public health. 2019;172:22-30. Doi:10.1016/j.puhe.2019.03.023

2. Dalton $\mathrm{K}$, Byrne S. Role of the pharmacist in reducing healthcare costs: current insights. Integrated Pharmacy Research \& Practice. 2017;6:37-46. Doi: 10.2147/IPRP.S108047

3. Okai GA, Abekah-Nkrumah G, Asuming PO. Determinants of community pharmacy utilization in Ghana. Journal of Pharmaceutical Health Services Research. 2020;11(2):159165. Doi: $10.1111 /$ jphs. 12338

4. Hashmi FK, Hassali MA, Khalid A, Saleem F, Aljadhey $H$, Bashaar M. A qualitative study exploring perceptions and attitudes of community pharmacists about extended pharmacy services in Lahore, Pakistan. BMC Health Services Research. 2017;17(1):1-9. Doi:10.1186/s12913-017-2442-6

5. Scahill SL, Atif M, Babar ZU. Defining pharmacy and its practice: a conceptual model for an international audience. Integrated Pharmacy Research \& Practice. 2017;6:121-129. Doi: 10.2147/IPRP.S124866

6. Blondal AB, Sporrong SK, Almarsdottir AB. Introducing Pharmaceutical Care to Primary Care in Iceland-An Action Research Study. Pharmacy.2017; 5(2):23. https://doi. org/10.3390/pharmacy5020023.

7. Lin $\mathrm{HW}$, Lin $\mathrm{CH}$, Chang $\mathrm{CK}$, Chou $\mathrm{CY}, \mathrm{Yu}$ IW, Lin CC, et al. Economic outcomes of pharmacist-physician medication therapy management for polypharmacy elderly: a prospective, randomized, controlled trial. Journal of the Formosan Medical Association. 2018;117(3):235-243. Doi: $10.1016 / j$. jfma.2017.04.017
8. Asayut N, Sookaneknun $\mathrm{P}$, Chaiyasong $\mathrm{S}$, Saramunee K. Outcomes, costs and stakeholders' perspectives associated with the incorporation of community pharmacy services into the National Health Insurance System in Thailand: a systematic review. International Journal of Pharmacy Practice. 2018;26(1):16-27.

9. Malau-Aduli BS, Alele FO, Heggarty P, Reeve C, Teague PA. Key elements of effective postgraduate GP educational environments: a mixed methods study. BMJ open. 2021;11(2):e041110.

10. Nisa ZU, Zafar A, Sher F. Assessment of knowledge, attitude and practice of adverse drug reaction reporting among healthcare professionals in secondary and tertiary hospitals in the capital of Pakistan. Saudi Pharmaceutical Journal. 2018;26(4):453461. Doi:10.1016/j.jsps.2018.02.014

11. Javeed A, Mahmood KT. Community pharmacy practice in Pakistan: from past to present-a review. Journal of Pharmaceutical Sciences and Research. 2012;4(2):1703-1708.

12. MoH: Malaysia Health Statistic: Number of Pharmacist and Ratio. 2008,. https:// micpohling.wordpress.com/2008/03/08/ malaysia-health-statistic-number-ofpharmacist-and-ratio/. Accessed September 18, 2020.

13. Iqbal Q, Bashir S, Iqbal J, Iftikhar S, Godman B. Assessment of medication adherence among type 2 diabetic patients in Quetta city, Pakistan. Postgraduate medicine. 2017;129(6):637-643. Doi: 10.1080/00325481.2017.1328251

14. Khan MS, Mehsud S, Dar R. A qualitative evaluation of new emerging role and challenges for community pharmacist in Pakistan: A case study report. African Journal of Pharmacy and Pharmacology. 2017;11(21):266-270. Doi:10.5897/AJPP2017.4754

15. Akutey R, Der R, Owusu-Daaku F, Baiden F. Using community pharmacies to expand access to screening for noncommunicable diseases in suburban Ghana-A facility-based survey on client needs and acceptability. Health Science Reports. 2018;1(9):e79. Doi:10.1002/hsr2.79

16. Aftab K. Clinical Pharmacy in Pakistan. Pharmaceutical Drug Regulatory Affairs 
Journal. 2019;2(1): 000111.

17. Khan AA. 15th International Pharmacy Conference and Exhibition. Lahore Pakistan Pharmacy Association. 2009.

18. Ahmad A, Patel I, Mohanta GP, Balkrishnan R. Evaluation of self medication practices in rural area of town Sahaswan at Northern India. Annals of Medical and Health Sciences Research. 2014;4(8):73-78.Doi: 10.4103/2141-9248.138012

19. Marathe PA, Kamat SK, Tripathi RK, Raut SB, Khatri NP. Over-the-counter medicines: Global perspective and Indian scenario. Journal of Postgraduate Medicine. 2020;66(1):28-34. Doi : 10.4103/jpgm.JPGM_381_19

20. Maqbool S. Ban on over-the-counter sale of antibiotics. https://www.thenews.com.pk/ print/464111-ban-on-over-the-counter-saleof-antibiotics. Accessed September 18, 2020.

21. Brandão GR, Teixeira L, Araújo L, Paúl C, Ribeiro O. Self-medication in older european adults: Prevalence and predictive factors. Archives of Gerontology and Geriatrics. 2020;91:104189. Doi:10.1016/j.archger. 2020.104189

22. Burns A, Goodlet KJ, Chapman A, Roberts EP. A case report of self-medication with over-the-counter fish antibiotic: Implications for pharmacists. Journal of the American Pharmacists Association. 2020;60(4):e1213. Doi: $10.1016 /$ j.japh.2019.12.020

23. Nations T. Health care in Pakistan. https:// nation.com.pk/13-Apr-2015/healthcarein-pakistan\#: : text=In rural health the emphasis, Units and Rural Health Centres.\&text=Health facilities in Pakistan are, water supply\%2C and adequate sanitation. Accessed September 16, 2020.

\section{Authors Contribution:}

Muhammad Hamza Rana: Idea conception, data collection, data analysis, and manuscript Writing.

Muhammad Husnain: Data collection, design of the work and acquisition.

Muhammad Hamza Iqbal: Correction and revision

Noor-i-Kiran Naeem: Idea conception, data analysis and manuscript Writing.

Muhammad Usman: Data analysis, final approval of the manuscript to be published.

Yasir Yaqoob: Data compilation and critical analysis.

Submitted for Publication: 26-01-2021

Accepted After revision : 15-06-2021 